\title{
Determinants of the Accessibility of Elderly Adults to Primary Health Care Services in Cameroon
}

\author{
Rogers A. Ajeh ${ }^{1,2, *}$, Jackson Jr. Ndenkeh" ${ }^{2,5}$, Akindeh Mbuh Nji ${ }^{2,3}$, Adebola Adedimeji ${ }^{4}$, Habakkuk A. Yumo ${ }^{2,5}$ \\ ${ }^{1}$ Faculty of Health Sciences, University of Buea, Buea, Cameroon \\ ${ }^{2}$ Research for Development International, Yaoundé, Cameroon \\ ${ }^{3}$ Department of Biochemistry, Faculty of Sciences, University of Yaoundé I, Yaoundé, Cameroon \\ ${ }^{4}$ Albert Einstein College of Medicine, New York City, United States of America \\ ${ }^{5} \mathrm{CIH}^{\mathrm{LMU}}$ Center for International Health, University Hospital, LMU Munich, Germany \\ *Corresponding author: rogers.ajeh@gmail.com
}

Received April 11, 2019; Revised May 14, 2019; Accepted June 10, 2019

\begin{abstract}
Introduction: The size of the elderly population continues to increase rapidly in developing countries. Unfortunately, these countries are often least prepared to meet the health challenges of rapidly ageing population. The old are characterized by chronic non-communicable disease burden and disability, thus requiring opportunities for regular health care. Yet these older persons are believed to lack access to even basic healthcare services. The objective of this study was to identify the determinants of access of the elderly to healthcare services in Cameroon. Methods: We carried out a cross sectional study on 316 elderly persons using a cluster sampling method in two Health Districts chosen conveniently to represent the rural and urban contexts of Cameroon. Factors associated with access to primary health care services were evaluated using Chi squared test and logistic regression. Significance level was set at 5\%. Results: Amongst the participants, $45.9 \%$, reported to have gone for medical care within the past year. Almost half of the study population could not remember when they had their last blood sugar test (54.4\%) and blood pressure test (43.0\%). As concerns HIV testing, 67.5\% had ever done an HIV test in their entire life. Furthermore, $26.1 \%$ of women and $20.0 \%$ of men have at least once done a breast cancer and prostate cancer screening respectively, with the rates being significantly higher for the urban setting $(42.3 \%$ vs $32.9 \%, \mathrm{p}<0.001)$. Lastly, accessibility to primary health care services was significantly associated with employment category and availability of a person to accompany the elderly to the hospital. Conclusion: This study showed that more than half of elderly lacked access to basic primary healthcare services. Employment category and availability of person to accompany elderly to the hospital were associated with access to healthcare services, while the setting (urban/rural) was associated with access to prostate and breast cancer screening. There is thus a need to improve access to primary healthcare services for elderly in Cameroon and the aforementioned factors should be considered when designing strategies to improve their accessibility. Larger scaled studies are needed to underscore other factors associated with access that could not be identified by this study.
\end{abstract}

Keywords: accessibility, elderly adults, HIV screening, health care services, Cameroon

Cite This Article: Rogers A. Ajeh, Jackson Jr. Ndenkeh, Akindeh Mbuh Nji, Adebola Adedimeji, and Habakkuk A. Yumo, "Determinants of the Accessibility of Elderly Adults to Primary Health Care Services in Cameroon.” American Journal of Public Health Research, vol. 7, no. 3 (2019): 102-110. doi: 10.12691/ajphr-7-3-3.

\section{Introduction}

Ageing refers to a multidimensional process of physical, psychological, and social change. The United Nations (UN) has not adopted a standard criterion, but generally use 60+ years to refer to the older population [1]. Age classification varied between countries and over time, reflecting in many instances the social class differences or functional ability related to the workforce, but more often than not was a reflection of the current political and economic situation. Many times the definition is linked to the retirement age, which in some instances, was lower for women than men. In contrast to the chronological milestones which mark life stages in the developed world, old age in many developing countries is seen to begin at the point when active contribution is no longer possible." [2]. The more traditional African definitions of an elder or 'elderly' person correlate with the chronological ages of 50 to 65 years, depending on the setting, the region and the country [3,4]. Population ageing is one of humanity's greatest triumphs and at same time one of the greatest challenges [5]. The absolute number of older people is increasing. Projections show that the elderly could account for $4.5 \%$ of the population by 2030 and nearly $10 \%$ of the population by 2050 [4]. This population ageing is fastest in developing countries, including countries with large populations of young people [6]. 
Older people have different requirements from society and government as opposed to young people [7]. While the effects on society are complex, there is a concern about the impact on health care demand and accessibility. Sub Saharan Africa has the greatest population ageing rate with about 36.6 million elderly people and, by 2025; their numbers will have almost doubled to 63 million [8]. By mid-century the number would have reached 141 million, which was a more rapid increase than for any other age-group [8]. Developing countries are often least prepared to meet the challenges of rapidly ageing societies [9]. In Cameroon between 1950-1955 and 1990-2000, there was a spectacular decrease in mortality, causing life expectancy to increase from 36 years to 50 years, which is a gain of 15 years in roughly 45 years [10]. These life expectancy continues to increase (53years in men and 54years in women in 2012) while fertility rate drops. According to United Nations Population Fund (UNFPA) in 2012 as well as the Demographic and Health Surveys [DHS] program in 2011, Cameroon had a 5\% proportion of people above 60years. The consequences of this demographic change is an increase in the number of older people requiring additional health care services owing to their increased vulnerability to chronic diseases and other disease states.

With ageing comes an increased risk of developing chronic diseases and disability [cancers, arthritis, heart diseases, stroke, osteoporosis, dementia, depression] [11]. Of the roughly 150,000 people who die each day across the globe, about two thirds (100,000 per day) die of age-related causes [11]. The medical care needs of older adults are often considerable. Approximately $80 \%$ of older adults require ongoing care for at least one chronic condition, $50 \%$ have multiple chronic conditions, and 60\% are managing three or more prescription medications [12]. Even in the absence of chronic illness, older adults' need to access medical care for acute conditions as they arise, as well as for extensive preventive care services recommended by evidence-based guidelines. [13] Unfortunately this growing elderly population with high disease burden stands a high risk of unmet medical needs. According to Ngwingmako et al in 2013, health and well-being are priority problems of elderly persons in Cameroon, and the challenges related to the same include lack of access to health care; poor nutrition and poverty; and lack of care for older people suffering from HIV/AIDS [14].

Despite the rapidly growing population of this vulnerable group in developing countries, the governments of these countries are often least prepared to meet their needs [9]. Cameroon has limited social security measures to meet up with the needs of her rapidly growing elderly population. Most commonly, social security for the elderly in Cameroon is provided by state through the pension system which covers only a very little proportion [5.4\%] of the elderly population [15]. Moreover, as per the provisions of the Cameroon 2001-15 health sector strategy [16], which have as one of its objectives (in line with the MDGs) to reduce morbidity by $1 / 3$ in poor vulnerable populations, priority is given to pregnant women and children less than 5 years but not to the elderly, who are as much vulnerable. Furthermore the Cameroon 2011 demographic and health survey [17] does not give any helpful information on this age group. Given the vulnerability of this population, given that access to healthcare is a major health determinant and considering the paucity of information in this domain, this study therefore seeks to identify the determinants of the accessibility of the elderly to healthcare services, and this in the rural and urban Cameroonian contexts.

Dealing with the increasing population of the elderly and chronic diseases burden requires opportunities for health promotion and disease prevention in the community as well as disease management within health care services. Many chronic diseases and the associated disabilities that affect the later part of a person's life span along with their economic and human costs can be prevented. But prevention requires reaching the individual before the disease takes hold and that means intervening early enough for appreciable impact. In order to prepare for unprecedented population ageing, it is of utmost importance that health systems in developing countries are prepared to address the consequences of these demographic trends. Ensuring availability and access to health services of minimum quality standard is one of the main functions of a health system and for this to be ensured all the internal and external influencing factors need to be taken into consideration.

This study aimed at assessing the accessibility of elderly persons to primary health care services in rural and urban contexts of Cameroon, going further to identify possible factors that influence this access. In this study, more attention has been given to their access to screening tests for Hypertension and diabetes; diseases with modifiable risk factors, age defining cancers such as prostate and breast cancer; and HIV/AIDS services.

\section{Methodology}

\subsection{Design and Setting}

This study was a cross-sectional descriptive and analytic, conducted in the Health Districts of Mbengwi and BiyemAssi, representing rural and urban contexts of Cameroon respectively. Data for the study was collected between January and February 2014. Mbengwi Health District is one of the Districts that make up the 19 health Districts in the North West Region, covers surface area of about $620 \mathrm{~km}^{2}$ and is bordered by Bamenda Health District to the North, Bali health District North East, Batibo health District to the East and South, while Njikwa and Bafut Health Districts to the West. The district has a population of about 54316 inhabitants distributed over 17 health areas, out of which 16 are rural areas with highly undulating landscape and very poor road networks. Over $80 \%$ of the population is made up of farmers and small-scale traders. The Health District of Biyem-Assi on the other hand is found in the Central region of Cameroon. This district is bordered to the North by the Health District of the Cité Verte, to the South and West by the Health District of Mbankomo and to the East by the Health District of Efoulan. Its surface area is $22 \mathrm{~km}^{2}$ and covers a total population of about 341180 inhabitants distributed over four health areas. 


\subsection{Study Population and Samples}

Our study population constituted persons aged 50 years and above called "elderly adults" and who have been living in their community for more than 5 years. The official retirement age in Cameroon is 55 years. However, a subset of professions (including government employees) have official retirement age at 50 . Furthermore, taking into account the fact that life expectancy at birth in Cameroon was 53 and 54 years for men and women respectively at the time this study was conducted, the elderly was therefore considered from the age of 50 years.

To calculate the sample size for this study, the below formula was used where $Z=Z$-value which is 1.96 , $\mathrm{p}=$ Anticipated access to health care services estimated at $75 \%$. The estimated access proportion was based on the results of a national survey carried in 2010 in Cameroon, estimating access to healthcare in the general population at $75 \%$ [18]. A proportion of $67 \%$ was found amongst elderly in Nigeria in 2015 [19], q= Anticipated non-accessibility set at 25\% (1-p) and $\alpha=$ Significance level set at 5\% which gave a minimum sample size of 289 . But since it was expected that access in elderly will likely be lower than $75 \%$ above, we rather considered the sample size using $67 \%$ from Nigeria in the below formula which gave a minimum of 340 .

$$
\mathrm{n}=\frac{Z^{2} p q}{\alpha^{2}}[20]
$$

The two Health Districts were chosen by convenience and a cluster sampling method was used to select the Bome community from Mbengwi Health District as a rural cluster and and Biyem Assi community from Biyem Assi Health District as an urban cluster respectively. Furthermore, a combination of a snowball and door to door strategy was used to recruit the participants from the clusters. A door-to-door strategy was used to identify the first participants and a combination of both strategies was used to identify subsequent. However, the door to door and the snowball were most applicable in the urban and rural setting respectively. The combination of both strategies was the appropriate as there was no existing database from which participants 50yrs+ and living in the communities for 5yrs+ prior study could be randomly selected. In total, a sample of 370 elderly adults was recruited out of which, 54 were rejected due to missing data at a rate greater than $5 \%$, giving a final sample size of 316. Face-to-face interviews were done during which for each participant, upon signed informed consent, a pre-tested questionnaire was administered. Despite not being a standard questionnaire, this questionnaire was developed as adaptation from literature as well as questions used in other research studies which assessed health care service accessibility in other contexts. This developed questionnaire which constituted a series of questions to capture information on participants' socio-demographic characteristics, medical history, access to primary healthcare service and access to screening for specific chronic diseases including hypertension, diabetes, HIV, breast and prostate cancer. The questionnaire was pre-tested on 15 persons in the urban and rural setting and was judged to be good enough to give a generalized idea on three of the basic concepts of access to health care services with information best acquired from the population (geographical accessibility, utilization and affordability). Two trained research assistants administered the questionnaire in both the urban and rural communities.

The collected questionnaire was entered, screened and analyzed using Epi Info v7 and SPSS. After performing a descriptive statistics with proportions for each variable, logistic regression was conducted first to estimate the unadjusted effects of the independent variables on access to primary health care services followed by an estimation of the adjusted effects in a plausible regression model [21]. Access to primary healthcare was defined as having been to a health facility for medical care at least once in the past 12 months. Thus, participants who reported having visited a health facility for medical care at least once within the past 12 months were considered to have access to primary healthcare while those who reported not having visited a health facility for medical care within the past one year were considered not having access to primary healthcare. Our definition of access is based on the generally recommended annual medical checkup for elderly, taking into consideration the fact that they are more prone to age defining diseases. The list of predetermined potential predictors of the accessibility of elderly adults to primary health care services in both rural and urban contexts of Cameroon used to perform the logistic regression included, setting, age group, marital status, religion, educational level, employment category, average monthly income, means to hospital, time to hospital, medical insurance, having telephone contact of a health personnel, person to accompany to hospital, transport difficulties, fear of another illness being discovered, fear of treatment not working, not able to communicate signs and symptoms to health personnel and fear of expensive bills. The above independent variables were computed in dummies with significance set at $5 \%$.

\section{Results}

As shown on Table 1 below, a total number of 316 elderly adults were included in this study comprising 134 and 182 from Mbengwi and Biyem-Assi districts respectively. The study population constituted of 146 (46.2\%) participants of female gender, 229 (70.3\%) in the 55-65yrs age group and 193 (61.9\%) were married. Concerning education, 256 (80.4\%) had at least the primary level of education, with 63 (17.8\%) getting up to secondary and higher level of education. Concerning the economic characteristics of the participants as shown on Table 2 below, the following was noted: Quite a significant proportion of participants were workers, employers or owning business (es) while 67 (21.2\%) were retired. Also 88 (28.5\%) of them were earning an average monthly income less than 50,000 FCFA ( $<\$ 90$ approx.). Their main sources of income varied from salary, pension, children support, rents and business. About 194 (62.9\%) owned a house of their own. It is worth noting that 147 (51.4\%) indicated that the revenue they earned was insufficient for their basic needs. Concerning their medical history, 169 (52.8\%) reported to have had a health problem within the past 6 months. The most frequently reported medical problems were chronic pain and lack of 
energy (asthenia) with up to 133 (42.0\%) of them reporting that it affected their ability to walk around. Furthermore, it was noted that only 45 (13.3\%) were actually covered by a medical insurance out of which 41 (91.1\%) were from Biyem-Assi (Table 3).

Regarding access to primary health care services in general, the following were noted as shown on Table 4. Out of the 318 elderly adults included in the study, 143 (45.9\%) reported having visited the hospital for health care services within the past one year, out of which 30 (21.2\%) were able to make up to 3 visits. When asked the means they usually take to get to the hospital, the two main means were public transport and trekking reported at 49.1\% (161) and 37.6\% (105), respectively. Furthermore, $12.2 \%$ and $62.9 \%$ of participants in the urban and rural setting, respectively, trekked to the hospital. Out of the 161 who reported using public transport to go to the hospital, up to 67 (41.6\%) indicated that it was hard to get a means of public transport when they needed it. It is also worth noting that 167 (53.8\%) spent more than 30mins to get to the hospital from their home. Also 125 (68.8\%) of the participants who reported having a medical problem within the past 6 months declared to have visited the hospital within the same period and out of which $28.6 \%$ (35) were attended to more than 2 days after they needed healthcare. Reasons for not going to the hospital despite a health problem included: no money for transport and/or consultation $(23,1 \%)$, attending a traditional practitioner (21,1\%), health problem not serious $(19,2 \%)$, opted for prayers in a local church $(11,5 \%)$, etc. It is worth noting that up to $88(84.6 \%)$ of those received in the hospital did not take the laboratory tests or drugs prescribed by the clinician with the most frequent reason being lack of money.

When some specific chronic diseases were selected, the following was noted as shown on Table 5 below. With respect to blood sugar and blood pressure measures, $54.4 \%$ and $43.0 \%$ respectively could not remember the last time the test was done. However, 101 (35.0\%) and
134 (43.3\%) reported having their blood sugar and blood pressure measured by a health personnel within the past three months. Furthermore, just 46 (26.1\%) of the women had ever done any breast cancer screening test before as well as $34(20.0 \%)$ of the men had ever done a prostate cancer screening test. The breast cancer test uptake proportions were $42.3 \%$ and $10.0 \%(p<0.0001)$ for the urban and rural setting respectively. The prostate cancer screening test uptake proportions were $32.9 \%$ and $7.1 \%$ $(\mathrm{p}<0.0001)$ for urban and rural setting. Regarding HIV testing, it was noted that 100 (32.5\%) of them had never done an HIV before while only 44 (14.2\%) had taken up an HIV test in less than a year. It is worth noting that only $31.9 \%$ ( $n=99$ ) reported not to have any sexual partner(s). It was also worth noting that only $30.1 \%(n=95)$ of the participants declared their healthcare providers often discussed HIV issues with them.

Concerning the unadjusted effects of the explanatory variables on access to healthcare services, it was noted that not being able to communicate signs and symptoms, person to accompany to the hospital and employment category were significantly associated with accessibility to primary health care services with p-values of 0.006, 0.002 and 0.015 respectively (Table 6). Other factors, despite not being of significant association, were also to be noted like educational level, fear of treatment, not working and average monthly income with p-values of 0.054, 0.08 and 0.082 respectively. When the 6 factors above were further computed for adjusted effects, it was noted that only employment category and availability of person to accompany to hospital were significantly associated with access to primary health care services with p-values of 0.014 and 0.023 respectively (Table 6). Elderly persons who have retired had a higher probability of accessing primary health care services than the other employment categories. In addition, elderly persons who had somebody to accompany them to the hospital had a higher probability of going to the hospital for health care services.

Table 1. Sociodemographic charachteristics of participants

\begin{tabular}{|c|c|c|c|c|c|c|}
\hline \multirow[t]{2}{*}{ Variable } & \multicolumn{2}{|c|}{ Mbengwi DH } & \multicolumn{2}{|c|}{ Biyem-Assi DH } & \multicolumn{2}{|c|}{ Total } \\
\hline & $\mathbf{N}$ & $\%$ & $\mathbf{N}$ & $\%$ & $\mathbf{N}$ & $\%$ \\
\hline \multicolumn{7}{|l|}{ Sex } \\
\hline Female & 50 & 37.3 & 96 & 52.8 & 146 & 45.0 \\
\hline Male & 84 & 62.7 & 86 & 47.3 & 170 & 55.0 \\
\hline \multicolumn{7}{|l|}{ Age group } \\
\hline $50-65 y$ yrs & 75 & 56.0 & 154 & 84.6 & 229 & 70.3 \\
\hline $65 y r s$ and above & 19 & 14.2 & 24 & 13.2 & 43 & 13.7 \\
\hline Unknown & 40 & 29.9 & 4 & 2.2 & 44 & 16.0 \\
\hline \multicolumn{7}{|l|}{ Marital status } \\
\hline Single & 5 & 3.7 & 7 & 3.9 & 12 & 3.8 \\
\hline Married & 90 & 67.2 & 103 & 56.6 & 193 & 61.9 \\
\hline Separated/Divorced & 13 & 9.7 & 25 & 13.7 & 38 & 11.7 \\
\hline Widow/widower & 26 & 19.4 & 47 & 25.8 & 73 & 22.6 \\
\hline \multicolumn{7}{|l|}{ Education level } \\
\hline No formal education & 32 & 23.9 & 28 & 15.4 & 60 & 19.6 \\
\hline Primary education & 77 & 57.5 & 32 & 17.6 & 109 & 37.5 \\
\hline Secondary education & 20 & 14.9 & 64 & 35.2 & 84 & 25.0 \\
\hline Higher education & 5 & 3.7 & 58 & 31.9 & 63 & 17.8 \\
\hline \multicolumn{7}{|l|}{ Religion } \\
\hline Catholic & 53 & 39.6 & 85 & 47.0 & 138 & 43.3 \\
\hline Protestant & 80 & 59.7 & 43 & 23.8 & 123 & 41.7 \\
\hline Muslim & 0 & 0.0 & 23 & 12.7 & 23 & 6.4 \\
\hline Animist & 0 & 0.0 & 16 & 8.8 & 16 & 4.4 \\
\hline Other & 1 & 0.8 & 14 & 7.7 & 15 & 4.2 \\
\hline
\end{tabular}


Table 2. Economic characteristics of participants

\begin{tabular}{|c|c|c|c|c|c|c|}
\hline \multirow[t]{2}{*}{ Variable } & \multicolumn{2}{|c|}{ Mbengwi DH } & \multicolumn{2}{|c|}{ Biyem-Assi DH } & \multicolumn{2}{|c|}{ Total } \\
\hline & $\mathbf{N}$ & $\%$ & $\mathbf{N}$ & $\%$ & $\mathbf{N}$ & $\%$ \\
\hline \multicolumn{7}{|l|}{ Employment category } \\
\hline Unemployed & 31 & 23.3 & 6 & 3.3 & 37 & 13.3 \\
\hline Salaried employee & 9 & 6.8 & 34 & 18.8 & 43 & 12.8 \\
\hline Employer & 2 & 1.5 & 34 & 18.8 & 36 & 10.1 \\
\hline Business & 31 & 23.3 & 40 & 22.1 & 71 & 22.7 \\
\hline Retired & 27 & 20.3 & 40 & 22.1 & 67 & 21.2 \\
\hline Other & 33 & 24.8 & 27 & 14.9 & 60 & 19.9 \\
\hline \multicolumn{7}{|c|}{ Average monthly income (CFA) } \\
\hline < 50000 (10 USD) & 43 & 32.1 & 45 & 24.9 & 88 & 28.5 \\
\hline 50000-90000 (10-180USD) & 5 & 3.7 & 24 & 13.3 & 29 & 8.5 \\
\hline >90000 (>180USD) & 9 & 6.7 & 46 & 25.4 & 55 & 16.1 \\
\hline Not determined & 77 & 57.5 & 66 & 36.5 & 143 & 47.0 \\
\hline \multicolumn{7}{|l|}{ Source of income } \\
\hline Pension & 19 & 14.2 & 36 & 19.8 & 55 & 17.0 \\
\hline Salary & 15 & 11.2 & 37 & 20.3 & 52 & 15.8 \\
\hline Children & 65 & 48.5 & 22 & 12.1 & 87 & 30.3 \\
\hline Rents & 3 & 2.2 & 11 & 6.0 & 14 & 4.1 \\
\hline Business & 30 & 22.4 & 56 & 30.8 & 86 & 26.6 \\
\hline Others & 2 & 1.5 & 20 & 11.0 & 22 & 6.2 \\
\hline \multicolumn{7}{|l|}{ House tenue } \\
\hline Self owned & 98 & 73.1 & 96 & 52.8 & 194 & 62.9 \\
\hline On rent & 36 & 26.9 & 86 & 47.3 & 122 & 37.1 \\
\hline \multicolumn{7}{|l|}{ Economic hardship } \\
\hline More than enough & 0 & 0.0 & 39 & 21.7 & 39 & 10.8 \\
\hline Enough & 25 & 18.8 & 102 & 56.7 & 127 & 37.7 \\
\hline Insufficient & 108 & 81.2 & 39 & 21.7 & 147 & 51.4 \\
\hline
\end{tabular}

Table 3. Medical history of participants

\begin{tabular}{|c|c|c|c|c|c|c|}
\hline \multirow[t]{2}{*}{ Variable } & \multicolumn{2}{|c|}{ Mbengwi DH } & \multicolumn{2}{|c|}{ Biyem-Assi DH } & \multicolumn{2}{|c|}{ Total } \\
\hline & $\mathbf{N}$ & $\%$ & $\mathbf{N}$ & $\%$ & $\mathbf{N}$ & $\%$ \\
\hline $\begin{array}{l}\text { Have had at least a medical problem for the past } 6 \text { months } \\
\text { Type of problem }\end{array}$ & 65 & 48.5 & 104 & 57.1 & 169 & 52.8 \\
\hline Paralysis & 1 & 1.9 & 13 & 15.7 & 14 & 8.8 \\
\hline Chronic pain & 19 & 36.5 & 26 & 31.3 & 45 & 33.9 \\
\hline Lack of energy & 17 & 32.7 & 22 & 26.5 & 39 & 29.6 \\
\hline Chronic illness & 7 & 13.5 & 8 & 9.6 & 15 & 11.6 \\
\hline Others & 8 & 15.4 & 14 & 16.9 & 22 & 16.1 \\
\hline Medical problem affecting ability to walk & 51 & 38.6 & 82 & 45.3 & 133 & 42.0 \\
\hline Covered by a medical insurance & 4 & 3.1 & 41 & 23.6 & 45 & 13.3 \\
\hline
\end{tabular}

Table 4. Access to primary health care services in a general context

\begin{tabular}{|c|c|c|c|c|c|c|}
\hline \multirow[t]{2}{*}{ Variable } & \multicolumn{2}{|c|}{ Mbengwi DH } & \multicolumn{2}{|c|}{ Biyem-Assi DH } & \multicolumn{2}{|c|}{ Total } \\
\hline & $\mathbf{N}$ & $\%$ & $\mathbf{N}$ & $\%$ & $\mathbf{N}$ & $\%$ \\
\hline Been to hospital for medical care within the past year & 62 & 46.3 & 81 & 45.5 & 143 & 45.9 \\
\hline If yes how many times? & & & & & & \\
\hline One time & 16 & 25.8 & 38 & 46.3 & 54 & 36.1 \\
\hline Two times & 31 & 50.0 & 29 & 35.4 & 60 & 42.7 \\
\hline Three time and more & 15 & 24.2 & 15 & 18.3 & 30 & 21.2 \\
\hline How do you get to the hospital? & & & & & & \\
\hline Trek & 83 & 62.9 & 22 & 12.2 & 105 & 37.6 \\
\hline Public transport & 43 & 32.6 & 118 & 65.6 & 161 & 49.1 \\
\hline Private transport & 6 & 4.6 & 40 & 22.2 & 46 & 13.4 \\
\hline How much time do you use to reach the hospital? & & & & & & \\
\hline Less than 30mins & 70 & 57.9 & 61 & 34.5 & 131 & 46.2 \\
\hline 30mins-1hr & 42 & 34.7 & 110 & 62.2 & 152 & 48.4 \\
\hline More than $1 \mathrm{hr}$ & 9 & 7.4 & 6 & 3.4 & 15 & 5.4 \\
\hline For a medical problem within the past 6 months went to the hospital & 52 & 71.2 & 73 & 66.4 & 125 & 68.8 \\
\hline The same day & 18 & 34.6 & 36 & 50.0 & 54 & 42.3 \\
\hline The next day & 18 & 34.6 & 17 & 23.6 & 35 & 29.1 \\
\hline More than 2 days later & 16 & 30.8 & 19 & 26.4 & 35 & 28.6 \\
\hline Take up of lab tests/medications & & & & & & \\
\hline No lab test/medication prescribed & 1 & 1.9 & 3 & 5.8 & 4 & 3.8 \\
\hline Took prescribed lab tests/Medications & 7 & 13.5 & 26 & 50.0 & 33 & 31.7 \\
\hline Did not take prescribed lab tests/medications & 44 & 84.6 & 44 & 60.3 & 88 & 72.4 \\
\hline Have the contact of health personnel you can call & 25 & 18.7 & 54 & 29.8 & 79 & 24.2 \\
\hline
\end{tabular}


Table 5. Access to primary health care services in specific disease situations

\begin{tabular}{|c|c|c|c|c|c|c|}
\hline \multirow[t]{2}{*}{ Variable } & \multicolumn{2}{|c|}{ Mbengwi DH } & \multicolumn{2}{|c|}{ Biyem-Assi DH } & \multicolumn{2}{|c|}{ Total } \\
\hline & $\mathbf{N}$ & $\%$ & $\mathbf{N}$ & $\%$ & $\mathbf{N}$ & $\%$ \\
\hline \multicolumn{7}{|c|}{ The last time your blood/sugar level was measured } \\
\hline One month & 21 & 15.9 & 24 & 14.8 & 45 & 15.4 \\
\hline Two months & 26 & 19.7 & 10 & 6.2 & 36 & 12.9 \\
\hline Three months & 8 & 6.1 & 12 & 7.4 & 20 & 6.7 \\
\hline More than three months & 6 & 4.6 & 27 & 16.7 & 33 & 10.6 \\
\hline Don't remember & 71 & 53.8 & 89 & 54.9 & 160 & 54.4 \\
\hline \multicolumn{7}{|c|}{ The last time your blood pressure was measured } \\
\hline One month & 21 & 16.0 & 33 & 18.5 & 54 & 17.3 \\
\hline Two months & 30 & 22.9 & 27 & 15.2 & 57 & 19.0 \\
\hline Three months & 5 & 3.8 & 18 & 10.1 & 23 & 7.0 \\
\hline More than three months & 8 & 6.1 & 38 & 21.4 & 46 & 13.7 \\
\hline Don't remember & 67 & 51.2 & 62 & 34.8 & 129 & 43.0 \\
\hline Have done breast cancer test before & 5 & 10.0 & 41 & 42.3 & 46 & 26.1 \\
\hline Have done prostate cancer test before & 6 & 7.1 & 28 & 32.9 & 34 & 20.0 \\
\hline \multicolumn{7}{|l|}{ The last time you did an HIV test before } \\
\hline Never done it before & 48 & 36.4 & 52 & 28.6 & 100 & 32.5 \\
\hline Less than a year & 20 & 15.2 & 24 & 13.2 & 44 & 14.2 \\
\hline $1-2 \mathrm{yrs}$ & 57 & 43.2 & 66 & 36.3 & 123 & 39.7 \\
\hline 2-3yrs & 3 & 2.3 & 17 & 9.3 & 20 & 5.8 \\
\hline 4yrs and above & 4 & 3.0 & 23 & 12.6 & 27 & 7.8 \\
\hline Often discuss HIV issues with my Doctor & 34 & 25.6 & 61 & 34.7 & 95 & 30.1 \\
\hline \multicolumn{7}{|l|}{ Number of sexual partners } \\
\hline No sexual partner & 48 & 35.8 & 51 & 28.0 & 99 & 31.9 \\
\hline One sexual partner & 0 & 0.0 & 81 & 44.5 & 81 & 22.3 \\
\hline Multiple sexual partners & 0 & 0.0 & 18 & 9.9 & 18 & 4.9 \\
\hline No response & 86 & 64.2 & 32 & 17.6 & 118 & 40.9 \\
\hline
\end{tabular}

Table 6. Unadjusted and adjusted effects of determinants from a logistic regression

\begin{tabular}{|c|c|c|c|c|c|c|c|c|}
\hline \multirow{3}{*}{ Categorical Variable } & \multicolumn{4}{|c|}{ Unadjusted effects } & \multicolumn{4}{|c|}{ Adjusted effects } \\
\hline & \multirow[t]{2}{*}{$\mathrm{P}$ value } & \multirow[t]{2}{*}{ OR } & \multicolumn{2}{|c|}{ 95\% C.I.for OR } & \multirow[t]{2}{*}{$P$ value } & \multirow[t]{2}{*}{ OR } & \multicolumn{2}{|c|}{ 95\% C.I.for OR } \\
\hline & & & Lower & Upper & & & Lower & Upper \\
\hline Not able to communicate (No vs Yes) & $0,006 *$ & 3.2 & 1.396 & 7.254 & 0.307 & 1.6 & 0.639 & 4.144 \\
\hline Person to accompany (No vs Yes) & $0,002 *$ & 7.0 & 2.043 & 23.844 & $0,023^{*}$ & 4.9 & 1.24 & 19.483 \\
\hline Employment (Reference is Others) & $0,015^{*}$ & & & & $0,014^{*}$ & & & \\
\hline Unemployed vs Others & 0.266 & 1.6 & 0.699 & 3.660 & 0.702 & 1.2 & 0.493 & 2.857 \\
\hline Salaried worker vs Others & 0.359 & 0.7 & 0.298 & 1.549 & 0.259 & 0.5 & 0.158 & 1.645 \\
\hline Employer vs Others & 0.09 & 0.5 & 0.182 & 1.131 & 0.414 & 0.6 & 0.214 & 1.886 \\
\hline Business vs Others & 0.431 & 1.3 & 0.66 & 2.650 & 0.612 & 1.2 & 0.572 & 2.578 \\
\hline Retired vs Others & 0.075 & 1.9 & 0.937 & 3.909 & 0.045 & 2.6 & 1.021 & 6.67 \\
\hline Education (Reference is Higher education) & 0.054 & & & & 0.106 & & & \\
\hline No formal education vs Higher education & 0.015 & 2.5 & 1.193 & 5.150 & 0.069 & 2.4 & 0.932 & 6.417 \\
\hline Primary education vs Higher education & 0.698 & 1.1 & 0.596 & 2.164 & 0.703 & 1.2 & 0.489 & 2.893 \\
\hline Secondary education vs Higher education & 0.211 & 1.5 & 0.784 & 3.014 & 0.169 & 1.7 & 0.79 & 3.849 \\
\hline Average income (Reference is Not determined) & 0.082 & & & & 0.119 & & & \\
\hline Less than 50000 frs vs Not determined & 0.041 & 0.6 & 0.328 & 0.977 & 0.054 & 0.5 & 0.26 & 1.011 \\
\hline 50000frs-90000frs vs Not determined & 0.115 & 0.5 & 0.222 & 1.177 & 0.228 & 0.5 & 0.186 & 1.494 \\
\hline More than 90000 frs vs Not determined & 0.792 & 1.1 & 0.579 & 2.048 & 0.721 & 1.2 & 0.465 & 3.024 \\
\hline Treatment not work (No vs Yes) & 0.08 & 1.7 & 0.942 & 2.895 & 0.776 & 1.1 & 0.558 & 2.183 \\
\hline
\end{tabular}

* Means the association is statistically significant (P value $<0,05$ ), OR stands for Odd Ratio and CI stands for Confidence Interval.

\section{Discussion}

The study showed that less than half of elderly had access to primary health care services within the past one year. A much lower proportion of them had access to blood sugar and blood pressure test. Access was lowest for breast and prostate cancer screening tests for women and men respectively, and this access was significantly lower in the rural compared to the urban setting. Employment category and availability of a person to accompany the elderly to the hospital were associated with accessibility of elderly to primary health care services. This inequity in access to primary health care service visà-vis the elderly in Cameroon, is at a period when disease control and health improvement is one of the country's strategic development priority [22]. This result bridges an important gap in knowledge on accessibility of elderly to primary health care services, considering the paucity of data on this subject in Cameroon. Moreover, Cameroon's demographic and health surveys do not prioritize nor 
give adequate information on elderly. Knowledge of the accessibility of the elderly to primary health care services and associated factors is needed to inform policies and guide health system strategies oriented towards improving accessibility of the elderly to primary health care services. Primary health care services should bring basic medical care to all subpopulations in a universal context, be it preventive, curative or palliative as well as taking into consideration need, accessibility, affordability and utilization [23]. It is very ironical that one of the greatest achievements which is increase in life expectancy has further led to another very important challenge which is access to primary health care services for the aging population [24]. This cross sectional study was thus conducted to assess the access of elderly persons to primary health care services as well as determine the influencing factors of the above accessibility in both the rural and urban contexts of Cameroon.

The socio-demographic characteristics of the participants revealed trends consistent with the literature in that majority of elderly in developing countries are known to live in the rural areas [25]. This observation is possibly due to the reverse urban - rural drift seen post retirement. Economic hardship was significantly higher in the rural setting as was the similarity in trend with respect to financial dependence. This indicated that elderly adults found in the rural setting had limited financial income thus increased hardship as compared to those from the urban setting. Furthermore, it was noted that just slightly above one-tenth (1/10) of the participants were older than 65years, suggesting a relatively low life expectancy in the study communities. This was in line with reality of the country, which had a life expectancy of 53 and 54 years for men and women respectively at the time of the study. This trend was also in line with WHO report [2015], classifying Cameroon amongst countries with percentage of person aged 60years being $0-9 \%$ of the total population [26]. Suboptimal quality of life and poor access to healthcare services amongst elderly may be accused for low life expectancy, suggesting a need to improve quality of life and accessibility to healthcare, not only for the elderly, but also for the general population.

Regarding access to primary health care services, participants had the general tendency to go to the hospital only when they were sick, and a considerable proportion of the participants did not seek formal healthcare services mainly due to believe in non-medical etiology of their illness and monetary constraints. The latter was greatly illustrated by the more than $70 \%$ not being able take the lab test(s) or drugs prescribed to them by their clinician due to lack of financial resources. There is a tendency of persons in need of health care services especially in developing countries to adopt other measures to acquire the services they need like self-medication, going to herbalists etc. which most at times are unproductive and even detrimental to their health [23]. Out of pocket payments for health services, economic hardship and certain superstitious health believes have been associated with health seeking behaviors [23]. The trends of access to care within 6 months period where similar with those of a study conducted by Alkhawaldeh et al in Jordan in the same year [both having about 68\% hospital visits within 6 months] [27]. However, the trends within past one year were much different, with a lower proportion in this study (45.9\%) in contrast to $73.8 \%$ in the latter study.

Regarding particular health care services, it was observed that even lower proportions of the participants had access to blood sugar and blood pressure measurements as well as HIV and cancer screening tests. These findings were quite striking as we would have expected the elderly adults especially those from the urban setting to visit the hospital more often for routine medical checkups. Despite being comparatively higher in the urban setting, uptake of breast and prostate cancer screening test were generally very low. The low breast cancer screening uptake was in line with findings of Mukupo et al back in 2007 in Zambia which showed a very low knowledge and uptake of breast cancer tests by women [28]. Also a systematic review in 2014 showed how the rural setting is disadvantaged as far as cancer testing infrastructure and personnel is concerned thus a logically low cancer testing uptake with respect to the urban setting [29]. This generally low cancer testing uptake could be associated to lower levels of education as well as awareness especially in the rural context as other studies in developing countries have shown low education as well as inadequate awareness and knowledge about cancers to be the individual factors linked to low cancer testing uptake be it female or male cancers [30,31,32]. The elderly are more predisposed to non-communicable diseases thus preventive measures coupled with early diagnosis will go a long way to reduce the burden in these participants [26]. Concerning HIV screening, same low trends of counseling and testing were noted meanwhile just about one third of them reported not to have a sexual partner. This means a significant proportion of the elderly are still sexually active, thus stand the risk of being exposed to STIs including HIV infection. The general tendency is that clinicians supposedly expect the elderly to be more responsible in their sexual life but this is not an ascertained fact taking into consideration that some of these elderly adults still remain sexually active [26].

Regarding determinants of access to primary health care services, it was observed that participants with somebody to accompany them to the hospital and those who were on retirement had a higher probability of visiting the hospital for medical care. Quite a considerate number of studies have been carried out in identifying the determinants of the access to primary health care services through which factors like age group, level of education, employment status and chronic illness have been found to be significantly associated to access to primary health care services $[27,28]$. The factors age group and education level differ in their influence on access to primary health care services with respect to the above study possibly as a result of the difference in age of recruitment in study as well as in education levels. Studies have also proven household poverty to be a limiting factor to access to health care services by the elderly [33] but due to the fact the monthly revenues of about half of the participants could not be determined, the above effect could not possibly be assessed with certainty. The above two identified determinants indicate that individual time availability and person to accompany should be taken into consideration with respect to offer of geriatric services. 
Home and community-based services have proven to greatly improve access to quality health care services especially in the rural setting [34].

This study was implemented only in two health Districts with the aim of assessing the situation in settings representing both the urban and rural contexts of the Cameroon. Despite the importance of the above findings and the fact that a cluster sampling strategy was used to select the study communities, the two health districts from which the sites where selected were chosen by convenience, thus weakening its inferential power in Cameroon. Also the potential determinants computed for association with accessibility to primary health care were mostly those linked to the participants themselves [since the study focused mostly on geographical accessibility, utilization and affordability of primary health services] and not the health system factors (availability of health care services). Thus, health system factors could not be ascertained from this study. Lastly, most quantifying healthcare accessibility variables were asked retrospectively for each participant thus being subjected to omission and recall bias. Thus, there is need of similar or complementary studies to be conducted on a larger scale in the country and/or sub region in order to provide more complete information and stronger evidences to help decision makers adjust their priorities with respect to primary health care availability, affordability and acceptability for the elderly.

\section{Conclusion}

A greater proportion of elderly do not have access to primary health care services in Cameroon including access to blood pressure, blood sugar, HIV, breast and prostate cancer screening tests. In addition, being a pensioner and the availability of a person to accompany the elderly to hospital are determinants of access to primary health care services. Accessibility to primary health care services vary with setting, with rural setting having a significantly lower access to prostate and breast cancer screening test compared to urban setting. Thus, there is a need for special provisions to improve access to primary healthcare services for elderly in Cameroon, while taking the rural-urban context into account. Provision of free or subsidized home healthcare services to the elderly, especially in the rural settings and a system of community relays and other community health workers providing geriatric health care services may significantly ameliorate healthcare amongst elderly. In the perspective of research advancement, there is need for similar and/or complementary studies using larger and more representative samples to provide more information on the individual, social, as well as health system determinants of accessibility of elderly to primary healthcare services in Cameroon.

\section{References}

[1] United Nations. Personal correspondence. January 2001. Marybeth Weinberger, UN.

[2] Gorman M. Development and the rights of older people. In: Randel J, et al., Eds. The ageing and development report: poverty, independence and the world's older people. London, Earthscan Publications Ltd., 1999: 3-21.
[3] World Health Organisation. Proposed working definition of an older person in Africa for the MDS Project, 2002. http://www.who.int/healthinfo/survey/ageingdefnolder/en/

[4] Kowal P, Chatterji S, Naidoo N, Biritwum R, Fan W, Lopez Ridaura R, et al. Data Resource Profile: The World Health Organization Study on global AGEing and adult health [SAGE]. Int J Epidemiol. 2012 Dec 1; 41[6]: 1639-49.

[5] WHO. Active aging: A policy framework. United Nations World Assembly on Ageing; April 2002; Madrid, Spain2002.

[6] UNDESA. World population policies. United Nations Publication: New York, 2013.

[7] Vincent JA. Understanding generations: political economy and culture in an ageing society. The British journal of sociology. 2005; 56 [4]: 579-99.

[8] Watkins K, Fu H, Fuentes R, Ghosh A, Giamberardini C, Johansson Cea. Human development report 2005. New York, USA: UNDP, 2005. ISBN 0-19-530511-6.

[9] WHO. Active ageing: Towards age-friendly primary health care. Geneva, Switzerland: WHO, 2004. ISBN 9241592184.

[10] UN. Political declaration and Madrid International plan of actionon ageing. World assembly on ageing; Madrid, Spain April 2002.

[11] De Grey ADNJ. Life Span Extension Research and Public Debate: Societal Considerations. Studies in Ethics, Law, and Technology 2007; 1[1].

[12] Bates DW, Cullen DJ, Laird N, Petersen LA, Small SD, Servi D, et al. Incidence of adverse drug events and potential adverse drug events. Implications for prevention. ADE Prevention Study Group. Jama. 1995; 274[1]: 29-34.

[13] Fiore AE, Shay DK, Broder K, Iskander JK, Uyeki TM, Mootrey G, et al. Prevention and control of seasonal influenza with vaccines: recommendations of the Advisory Committee on Immunization Practices [ACIP], 2009. MMWR Recommendations and reports: Morbidity and mortality weekly report Recommendations and reports. 2009; 58[RR-8]: 1-52.

[14] Ngwingmako RA. The elderly in Cameroon. Accademic journal. 2013; Vol. 23[Issue 3]: P2.

[15] Eyinga DEC, Mbarga B, D. AO. Situation socio-économique des personnes âgées au Cameroun. Yaounde, Cameroun: BUCREP, 2011.

[16] Stratégie Sectorielle de la Sante du Cameroun 2001 - 2015 minsante.

http: //www.minsante.cm/site/sites/default/ files/SSS_2001_2015_Doc_final.pdf.

[17] Cameroon Demographic and Health Survey. 2011. https: //dhsprogram.com/pubs/pdf/FR260/FR260.pdf

[18] National Institute of Statistics, Cameroon. 2010: $2^{\mathrm{E}}$ enquête sur le suivi des dépenses publiques et le niveau de satisfaction des bénéficiaires dans les secteurs de l'éducation et de la santé au Cameroun [PETS2].

http://www.statistics-cameroon.org/downloads/pets/2/ Rapport_principal_Sante_francais.pdf

[19] Chukwudi ON, Uyilewhoma IM, Chukwudi OE, Ebi EJ, Emmanuel OM, Kalu OO, et al. Determinants of Health Services Utilization among the Elderly in Calabar Municipality, Cross River State, Nigeria. Eur J Prev Med. 2015 Aug 1; 3[5]: 129.

[20] Bland M. Introduction to Medical Statistics. Oxford University Press. 2000; 3rd Edition[Chapter 18]: 400.

[21] Landau S, Everitt BS. A Handbook of Statistical Analysis using SPSS. London/New York: Chapman \& Hall/CRC Press LLC; 2004. $339 \mathrm{p}$.

[22] Nzima Nzima, Valery. Health Sector Strategy and Economic Development in Cameroon: History, Challenges and Perspectives. Thesis. Georgia State University. 2014. htp://scholarworks.gsu.edu/iph_theses/341

[23] Cumber SN, Ndenkeh NJJ, Tsoka-Gwegweni JM, Vukugah TA. Ameliorating access to primary health care services in Cameroon. Int J of Advanced Research. 2017[2320-5407]: 5.

[24] Rowe JW, P. FL. Meeting the Health Care Needs of Aging Societies. Brown Journal of World Affairs. 2013; Vol 20 [Issue 1].

[25] DeVoe JE, Wallace LS, Fryer GE, Jr. Patient age influences perceptions about health care communication. Family medicine. 2009; 41[2]: 126-33.

[26] WHO 2015 report on Ageing and Health.

[27] Alkhawaldeh A, Holm MB, Qaddumi J, Petro W, Jaghbir M, Al Omari O. A Cross-Sectional Study to Examine Factors Associated with Primary Health Care Service Utilization among Older Adults 
in the Irbid Governorate of Jordan. Current Gerontology and Geriatrics Research. 2014: 7.

[28] Mukupo FC, Mubita-Ngoma CA. Breast cancer knowledge and breast self examination practice among rural and urban women in Zambia. Africa Journal of Nursing and Midwifery. 2007: 9[1].

[29] Leung J, McKenzie S, Martin J, McLaughlin D. Effect of rurality on screening for breast cancer: a systematic review and metaanalysis comparing mammography. Rural and Remote Health. 2014.

[30] Crispin Kahesa et al. Determinants of acceptance of cervical cancer screening in Dar es Salaam, Tanzania. 2012
[31] Robert N Makori. Factors Associated with Uptake of Prostate Cancer Screening among Patients Seeking Health Care Services at Kenyatta National Hospital. A thesis submitted in 2015 at the University of Nairobi...

[32] Humphrey Nwobodo et al. Analysis of the determinants of low cervical cancer screening uptake among Nigerian women. 2015.

[33] Stephen Ojiambo Wandera et al. Determinants of access to healthcare by old persons in Uganda: a cross-sectional study. 2015

[34] Linnae Hutchison et al. Access to quality health services in rural areas-long-term care. 2010.

(C) The Author(s) 2019. This article is an open access article distributed under the terms and conditions of the Creative Commons Attribution (CC BY) license (http: //creativecommons.org/licenses/by/4.0/). 